\title{
Fasten Your Seat Belts!
}

\author{
Asma Ali Chookah
}

\author{
Student, Zayed University, Dubai
}

Learning and Teaching in Higher Education: Gulf Perspectives 2/2

\begin{abstract}
When the clock's hands point to 1:00 pm every Sunday and Tuesday, a journey beyond Zayed University's walls begins. It is an academic journey through the world of communication and media that merges education and entertainment together in a way that makes us always wait for it in anticipation. This journey is called COM 125 "World Communication Systems", which is a course where simple things can make a difference, and where there are no borders for imagination, creativity, ideas and thoughts. This course isolated us from the world of stress that occurs in the university atmosphere. COM 125 is a course with Dr. Jack Hillwig that introduced us to the College of communication and Media Sciences. It showed us how media determines who we are, what we think, and how we live. It made us aware of the power of media and its impact on ourselves. It is really the course that I learned the most from in my time in the university so far. It was a journey which took all my inner energy out and made me discover many things about myself that I had never thought of.
\end{abstract}

We started our journey by landing in Media Effects Land. In this land we looked at media as a story that affects our daily life. We realized that media not only shows us what is going on in the whole world, but also influences our values, behaviors, and beliefs, and determines our lifestyle and reactions. The real T.V show Star Academy is a good example of this. You can not imagine how this program stole people's hearts and minds: my sister knows the participants better than her lessons. If you want to know anything about them she will tell you the answer immediately. She dresses and speaks Lebanese and Tunisian since most of the participants were Lebanese and North Africans.

After discovering the land of media effects, we moved to Culture and Media Land. In this land we found out that the first motive of media is reflecting countries' cultures. In this land we quested for a treasure called "U.A.E Media" that is produced and created by U.A.E nationals. When we finally found it, we discovered that the U.A.E has its own production of media from books, magazines, newspapers, television, radio website and even movies. Yet we are not exposed to these because we always think that what others do is better than what we do. I hope that we will be able to change this ideology in the near future.

Ad Land was the largest and the most fantastic stop in our journey. Whenever media is mentioned, advertising pops up immediately in our minds. Advertising can persuade customers to purchase a specific brand or service by affecting them emotionally. For example, in shampoo advertisements, advertisers try to show the product as the best shampoo in the world. It makes your hair silky, shiny, and healthy. Isn't it interesting that all shampoo advertisements use the same words (silky, shiny, and healthy)? It is all about emotions. Through advertising, customers' attitudes towards a product or a company may be changed. In this land, we understood the power of branding and how it acts as a product identity. To complete our visit, we had to brand and advertise an ordinary Koosh Ball. We were divided into groups of three and worked together to transform the Koosh Ball into an incredible Hedgehog that has many uses for decoration, clothes, toys ...etc. Therefore, we passed the evaluation and we were able to leave Ads Land and fly to Story Land where we learned how to tell living stories.

Lovemarks Land was our sixth station. Lovemark was a new concept for us, so we searched for its meaning on the internet and we found that a lovemark is when you love a product or a brand and feel that you cannot live without it. It is a kind of relationship between you and the product. Any product can be a lovemark if it has mystery, sensuality, and intimacy. Let us take Burj Al Arab as an example. Its mystery is about it being the first seven-star hotel in the world. Sensuality arises even before entering it when you see its marvelous design that looks like an Arabian lute or a sail, while the sense of luxurious life and excellent service, which makes you feel like a king/queen, creates a feeling of intimacy. Starbucks, Pepsi, Patchi, Damas, and Red Bull are good examples of lovemarks too. The evaluation of this land was a little bit challenging. In a week, we had to bring a U.A.E Lovemark to life by designing a poster that contains the logo, the slogan, and how this lovemark meets the three categories: mystery, sensuality, and intimacy. I chose Mercato, a shopping mall in Dubai, to bring to life. So I went to Mercato and spent two hours in taking photographs and taking the business cards of all the stores there. Unfortunately, all the photographs were not clear at all and I had to go there again. This time I went to the souvenir shop and bought the postcards that have Mercato Pictures on them and took them to the stationery shop to enlarge them. The final result satisfied me with the title of "Where there is love there is life... (Mahatma Gandhi) Experience Mercato: The Good Life". It was my first experience at designing a poster as I am not good in designing at all, but I think it was pretty good.

We ended our journey by landing in Newspaper Land. We learned how newspapers get started in the U.A.E as well as the twelve factors in newsworthiness. The main thing that stuck in our minds from this land is that information is power. "The medium of you" was the title of our final assignment. In this assignment we had to explain five ways we feel that we could make our presence known in and contribute in the media industry. My first way is a magazine written in Braille for blind people that enables them to be aware of the latest world news. I will call it "Vision", "Al-Ro'ayah" in Arabic. "Made in U.A.E" is the second way. It is a Radio program that gives the opportunity for U.A.E nationals to direct and present their own radio 
program. The participants have to send their plans and we will choose among them. After that they will practice with the radio station staff for two days after the evaluation and they will record it. The program will be once a week in both Arabic and English languages for one hour and a half. It can be about any subject except game shows. At the end of the month, one of the four programs will win a prize. The aim of "Made in U.A.E" is to encourage ambitious U.A.E nationals to be involved in the field of communication and Media. There are thousands of T.V programs for women, so I thought of a program that would be different to be my third way. This program will be exclusively for men, showing fashion, cars, haircuts, accessories, health, sport, and more. Just watch "After Shave" and break the routine. I want to make this program to fly out of the flock. There will be discussions, interviews and the latest news for men in the U.A.E. It will be presented twice a week on Sundays and Tuesdays. "DJ Soul" is another radio program, which will contain only remixed music with top 10 remixes. I would like to reflect my talent in mixing music. The last way is a TV program "Exploring the U.A.E", which will highlight the position of the U.A.E in the world. It will talk about everything in the U.A.E: tourism, education, economy, media, festivals, social transitions, heritage, etc. It will make the U.A.E a place that everyone wants to explore.

Through this journey, as I have mentioned previously, I had a lot of fun besides the valuable information and new things we learned. What helped me to learn is the aim that our instructor Dr. Jack Hillwig, who sadly has left the university, taught us to set ourselves. This aim is to change the world and make people say "WOW!" He had always told us not to belittle what we do even if it was very simple. "Even if it is a small thing or does not mean anything for you" he said "It may mean something for others". He gave us the courage to explore the world of communication and media without giving any attention to stereotypes about women in the media industry. Media is all about expressing yourself and reflecting your thoughts in what you do.

You will never feel how great it is to succeed unless you have tried hard and overcome the obstacles that are on your way to reach it. My shyness was and still is the main barrier that I face. While presenting the Hedgehog activity, I can not tell you how nervous I was, but with the help of my partners, Khulood and Ameera, I overcame my shyness and tried to be as spontaneous as I could. With my friends' help, the advertisement looked very real and wonderful, and we deserved the A grade which we got for it. So, never think that your abilities are limited and do not be shy about your thoughts. Draw your goal and go for it. Do not be afraid of making mistakes because no one was born wise and knowing everything. If you want to learn you have to fall. It is what they call "the rise and fall".

COM 125 is the course in which I discovered myself. It developed my communication skills and rebuilt my self-confidence. And if you intend to enroll in this course, you have to bear in mind that you will enjoy the rewards of your achievements only if you work hard for it. If you are willing to do that, I am absolutely sure that you will know the meaning of being proud of your work. Thank you Dr.Hillwig for everything you did to make our will-power stronger than before. I am really honored to have had you as an instructor for this course, and I promise that I will try not only my best, but also the best of my best to change the world through Media. 